Article

\title{
Research of Particle Motion in a Two-Stage Slurry Transport Pump for Deep-Ocean Mining by the CFD-DEM Method
}

\author{
Xianghui Su ${ }^{1,2, *}$, Zhenji Tang ${ }^{1}$, Yi Li ${ }^{1}$, Zuchao Zhu ${ }^{1}$, Kamila Mianowicz ${ }^{3}$ and Peter Balaz ${ }^{3}$ \\ 1 State-Province Joint Engineering Lab of Fluid Transmission System Technology, Zhejiang Sci-Tech University, \\ Hangzhou 310000, China; 201820503004@mails.zstu.edu.cn (Z.T.); liyi@zstu.edu.cn (Y.L.); \\ zhuzuchao@zstu.edu.cn (Z.Z.) \\ 2 Changsha Research Institute of Mining and Metallurgy, Co. Ltd., Changsha 410000, China \\ 3 Interoceanmetal Joint Organization, 71-233 Szczecin, Poland; k.mianowicz@iom.gov.pl (K.M.); \\ p.balaz@iom.gov.pl (P.B.) \\ * Correspondence: suxianghui@zstu.edu.cn
}

Received: 23 November 2020; Accepted: 17 December 2020; Published: 19 December 2020

check for updates

\begin{abstract}
The slurry transport pump is the key equipment of deep-ocean mining systems. The motion law of coarse particles in the pump is not clear enough. In this paper, a hydraulic model of a laboratory-scale two-stage slurry transport pump is constructed, and the motion characteristics of coarse particles in the pump are numerically studied by using the computational fluid dynamics-discrete element method (CFD-DEM) method. The performance curve of the pump is obtained by experimental measurement, and the reliability of the calculated results is verified. Due to the application of the amplification flow rate design method, the optimum efficiency point of the pump is shifted to the large flow rate condition. Differences in particle swarm within two stages are compared. The position distribution, velocity variation and trajectory of particles in the impeller and bowl diffuser are studied in detail. The velocity of particles leaving the impeller depends on whether they collide with the impeller blade. The motion of particles in the bowl diffuser is divided into three periods. Collision between particles and blades in the bowl diffuser not only leads to energy loss but also gradually transforms the circumferential velocity of particles into axial velocity in the second period. This work can provide a reference for the study of wear and blockage prevention of slurry transport pumps.
\end{abstract}

Keywords: slurry transport pump; particle motion; deep-ocean mining; CFD-DEM; bowl diffuser

\section{Introduction}

Seafloor mineral resources are abundant. Solid mineral resources have potential commercial exploitation value. They mainly include polymetallic nodules, cobalt-rich crusts, and polymetallic sulfides, whose reserves are tens to thousands of times higher than those on land [1-3]. Most of these mineral resources are stored at a depth of 5000 6000 m. For deep-ocean mining, the most commercially available method is to use a submarine mining robot to collect ore, and then to raise the ore to the surface mining ship by a riser [4,5], as seen in Figure 1. At present, air-lift and liquid-lift methods are the main vertical transport methods. The lack of direct control of the fluid and solid outputs in the air-lift method makes the stable continuous operation a hard task. The liquid-lift method is investigated by more scholars [6]. The system based on the liquid-lift method includes four subsystems: collecting, lifting, navigation, and communication and water surface support. The role of the lifting system is to transport the slurry collected by the mining system to the water surface support system, which is the most energy-consuming part of the entire deep-ocean mining process [7]. The slurry transport pump 
is the core component of the lifting system. Its reliability and working efficiency are directly related to the safety and economy of the entire deep-ocean mining system.
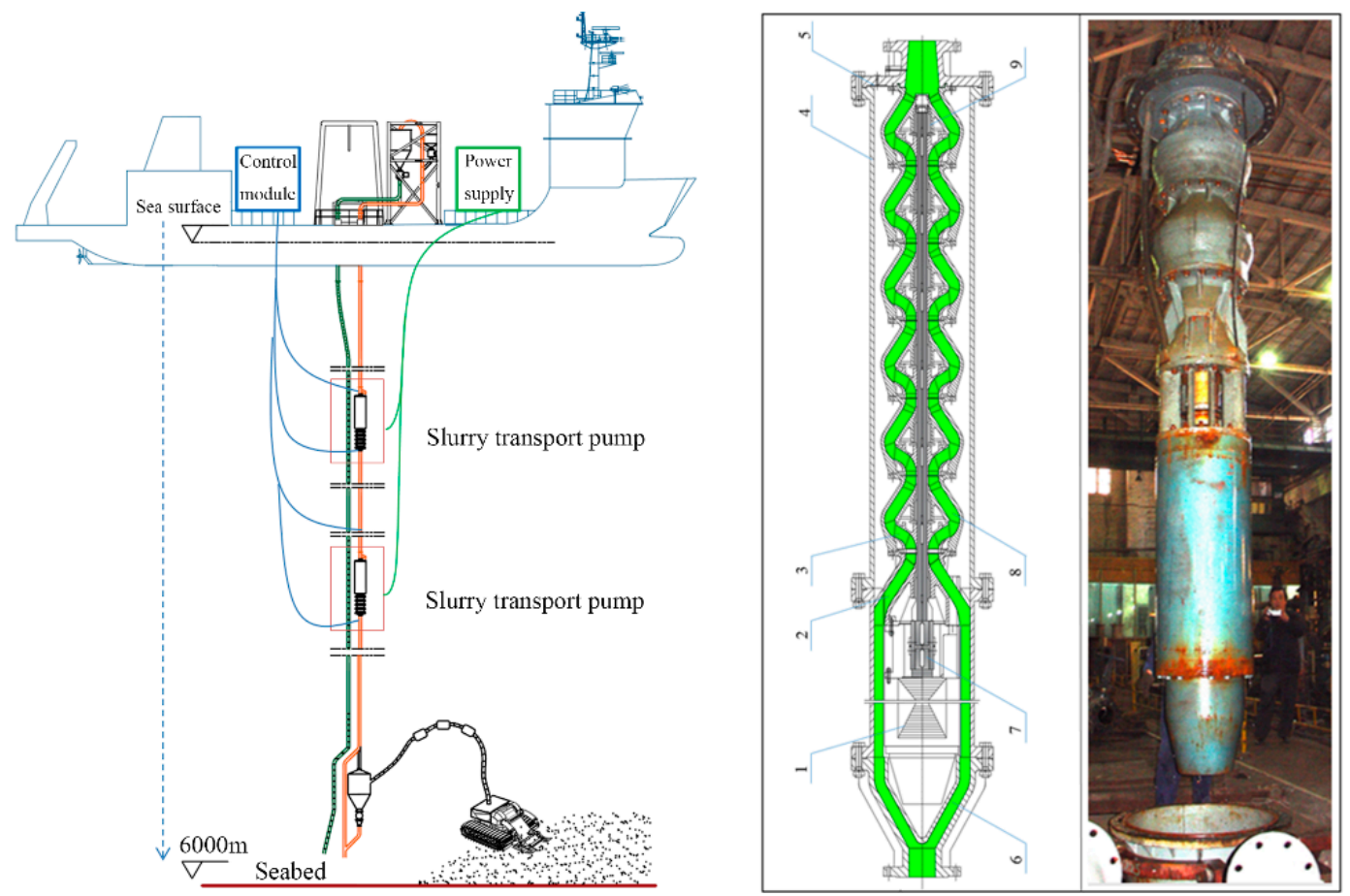

Figure 1. Schematic diagram of a deep-ocean mining system. Slurry transport pump: (1) submersible motor, (2) coupling pipe, (3) pump rotor, (4) out shell, (5) discharge, (6) suction, (7) shaft coupling, (8) diffuser, (9) and sliding bearing (no sealing).

The slurry transport pump is a multi-stage structure with a bowl diffuser, and its flow passage is complicated. There are three important engineering problems that need to be resolved when designing and manufacturing a slurry transport pump: overflow performance of mineral particles (non-blockage) [8,9]; reliability (wall wear) [10,11]; and efficiency issues (energy consumption). The three problems are all closely related to the motion of particles in the pump. Therefore, in order to solve the above engineering problems, it is necessary to study the kinematic information of particles such as position distribution, motion trajectory, velocity change, and so on.

Visual experiments are an important method to study solid-phase motion in the slurry pump. The distribution and velocity of solid phase have a great influence on the performance of the pump, so they are essentially the most studied issues. Cader et al. used Laser Doppler Velocimetry (LDV) to measure the velocity distribution of particles $(0.8 \mathrm{~mm})$ in the impeller and found that the radial velocity of solid particles at the outlet of the impeller was greater than the fluid but lagged the fluid in the circumferential direction [12]. They meanwhile studied the two-phase velocity distribution at the interface between the impeller and the volute and found that the velocity distribution at the interface could be used to evaluate the pump head-flow rate characteristic curve [13]. Shi et al. designed a new Particle Image Velocimetry (PIV) experimental device and developed a gray-scale-based particle recognition algorithm for measuring the solid-phase distribution in centrifugal pumps. The device avoids stirring to reduce the influence of bubbles on PIV measurement $[14,15]$. Some studies have linked the motion characteristics of the particles to the wear of the pump. Kadambi et al. used PIV to measure the velocity and kinetic energy fluctuations of the slurry $(0.5 \mathrm{~mm})$ in the tongue area [16]. The experimental results show that the random collision caused by the kinetic energy fluctuation of the solid phase is closely related to the wear of this region. Li et al. simplified the impeller passage into a curved tube and studied the relationship between coarse particle motion and wall wear [17]. 
However, visualization experiments are not applicable in many situations. There is a wider range of applications for numerical simulations. The Euler-Euler model is a method to take both the solid and liquid phases as continuous phases. Tarodiyaet et al. used this model to predict the head and efficiency of a centrifugal mud pump [18]. However, the model cannot capture the details of particle movement, so it is not suitable for applications with low solid-phase concentration or large particle size. The Euler-Lagrange method is the more common solid-liquid two-phase simulation method. The liquid phase is solved under the Euler framework and the solid phase is solved under the Lagrange framework. Zhu et al. studied the influence of particle density and particle size on wear of submersible pump using the Discrete Phase Model (DPM) [19]. Although the calculated results differ greatly from the experimental data in value, the wear pattern and position are in good agreement with the experiment. In the conventional DPM, the solid phase is point particles, and the collision between particles is considered by the hard ball model or directly ignored. On the contrary, the discrete element method (DEM) can obtain kinematic information of particles more accurately by using the soft ball model to calculate collisions of particle-particle and particle-wall. Huang et al. used the computational fluid dynamics (CFD)-DEM method to conduct transient numerical simulations of solid-liquid two-phase in a centrifugal pump and obtained volume fraction distributions and trajectories of the solid particles [20]. In recent years, the Lagrange-Lagrange method has also been applied to the simulation of solid-liquid phase. These methods take the liquid phase as a discrete phase. Ndimande et al. used the Discrete Element Method-Smoothed Particle Hydrodynamics (DEM-SPH) method to simulate the solid-liquid two-phase flow in a Stirred Media Detritor [21].

The volume concentration of solid phase is low in the slurry transport pump $(<10 \%)$ and particle size is large $(>10 \mathrm{~mm})$. The number of particles in the pump is small. So, it is of value to organize, classify, and analyze individual information (velocity and position) of the particle. A more detailed division of particle swarm in time and space is meaningful. In this paper, a laboratory-scale slurry transport pump was designed and manufactured, and then, its working characteristics were measured. After that, CFD-DEM was used in this paper to simulate the solid-liquid two-phase flow in this pump. Under the actual operating conditions $\left(Q=120 \mathrm{~m}^{3} / \mathrm{h}\right.$, the spatial distribution, velocity change, and trajectory of particles were studied with emphasis.

\section{Materials and Methods}

\subsection{Geometric Model}

The research object of this paper is a slurry transport pump for deep-ocean mining. It is a two-stage centrifugal pump with bowl diffusers. Due to the large size of the prototype pump, it is not suitable for experiments. Therefore, the geometric parameters of the prototype pump were reduced according to the principle of similar specific speed. Then, the test pump was designed according to the new parameters. The basic geometric parameters of the impeller and bowl diffuser are listed in Table 1. The main performance parameters of test pumps and prototype pumps are listed in Table 2 . The hydraulic model of the test pump is shown in Figure 2. The whole pump is placed vertically with the inlet at the bottom. The gravity direction is opposite to the flow direction at the pump inlet.

Table 1. Geometric parameters for the test centrifugal pump.

\begin{tabular}{cccc}
\hline Impeller & Value & Bowl Diffuser & Value \\
\hline Inlet diameter $(\mathrm{mm})$ & 135 & Inlet diameter $(\mathrm{mm})$ & 276 \\
Outlet diameter $(\mathrm{mm})$ & 272 & Inlet width $(\mathrm{mm})$ & 26 \\
Blade number & 4 & Blade number & 5 \\
Wrap angle $\left(^{\circ}\right)$ & $111 \sim 115$ & Wrap angle $\left(^{\circ}\right)$ & 118 \\
Outlet angle $\left(^{\circ}\right)$ & 24 & Outlet angle $\left(^{\circ}\right)$ & 25 \\
Inlet angle $\left(^{\circ}\right)$ & 26 & Inlet angle $\left(^{\circ}\right)$ & 90 \\
\hline
\end{tabular}


Table 2. Test pump and prototype pump performance parameters.

\begin{tabular}{cccc}
\hline Parameters & unit & Test Pump & Prototype Pump \\
\hline Design flow rate $(Q)$ & $\mathrm{m}^{3} / \mathrm{h}$ & 120 & 420 \\
Design head $(H)$ & $\mathrm{m}$ & 40 & 270 \\
Rotating speed $(n)$ & $\mathrm{rpm}$ & 1450 & 1450 \\
Specific speed $^{1}\left(n_{s}\right)$ & & 102.17 & 102.17 \\
\hline
\end{tabular}

${ }^{1}$ The specific speed was calculated according to the Chinese standard: $n_{s}=3.65 n \sqrt{\mathrm{Q}} / \mathrm{H}^{3 / 4}$, and the units of the variables in the above formula are $\mathrm{r} / \mathrm{min}, \mathrm{m}^{3} / \mathrm{s}$, and $\mathrm{m}$, respectively.

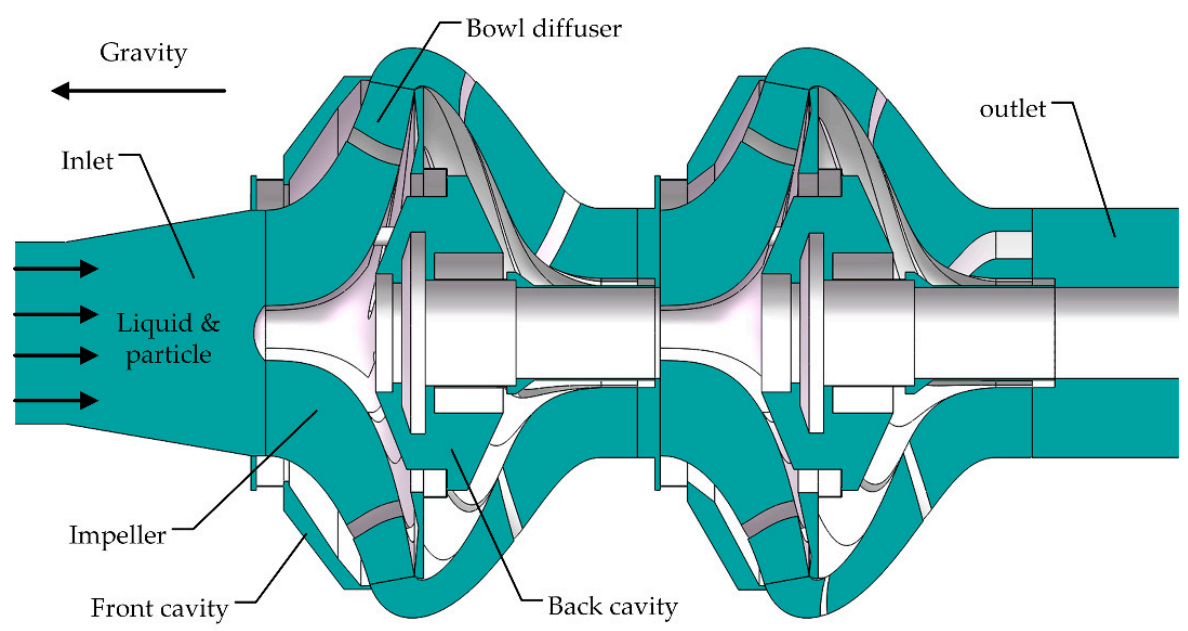

Figure 2. The two-stage hydraulic model.

\subsection{Basic Assumptions}

The prototype pump was installed at depths of 200 300 $\mathrm{m}$ and the environmental pressure was high. So, the possibility of cavitation was low. The following basic assumptions are stated: temperature changes and compressibility are not taken into account; there is no phase transition in the pump; the flow is uniform at the pump inlet; the solid phase is a spherical particle without deformation and breakage.

\subsection{Mathematical Model}

The CFD-DEM coupling method was used to solve the two-phase flow of coarse particles in the slurry transport pump. The liquid was treated as a continuous phase and modelled by the Reynolds-averaged Navier-Stokes (RANS) model. The locally averaged governing equations of mass and momentum are as follows [22,23]:

$$
\begin{gathered}
\frac{\partial}{\partial t}\left(\rho_{f}\right)+\operatorname{div}\left(\rho_{f} \boldsymbol{u}_{f}\right)=0 \\
\frac{\partial}{\partial t}\left(\rho_{f} \boldsymbol{u}_{f}\right)+\operatorname{div}\left(\rho_{f} \boldsymbol{u}_{f} \boldsymbol{u}_{f}\right)=-\operatorname{grad}(p)+\operatorname{div}\left(\tau_{f}\right)+\rho_{f} \mathbf{g}-\boldsymbol{F}_{f p}
\end{gathered}
$$

where $\rho_{f}$ is the fluid density; $t$ is the time; $\boldsymbol{u}_{f}$ is the fluid velocity vector; $p$ is the fluid pressure; $\tau_{f}$ is the viscous stress of the fluid. The fluid-particle interaction force, $\boldsymbol{F}_{f p}$, per unit fluid volume is:

$$
\begin{gathered}
\boldsymbol{F}_{f p}=\sum_{i=1}^{n_{c}} \frac{f_{f p, i}}{V_{c}} \\
\left.f_{f p, i}=-V_{p, i} \operatorname{grad}(p)+V_{p, i} \operatorname{div}\left(\tau_{f}\right)+f_{d, i}\right)
\end{gathered}
$$


Here, $c$ is the cell index and $i$ is the particle index. $V_{c}$ is the volume of the cell with index $c ; n_{c}$ is the number of particles in the cell with index $c ; V_{p, i}$ is the volume of the particle $i ; f_{d, i}$ is the drag force applied on particle $i$. The drag force of a particular particle is calculated by:

$$
\begin{gathered}
f_{d, i}=\frac{m_{p, i} v_{s, i}}{\tau_{v, i}} \\
\tau_{v, i}=\frac{2 m_{p, i}}{C_{d} \rho_{f} A_{p, i}\left|v_{s, i}\right|}
\end{gathered}
$$

Here, $\tau_{v, i}$ is the particle relaxation time [24]; $m_{p, i}$ is the particle mass; $v_{s, i}$ is the slide velocity and it is calculated by $\boldsymbol{v}_{s, i}=\boldsymbol{u}_{f}-\boldsymbol{v}_{p, i}$. For the above equation, $\boldsymbol{v}_{p, i}$ is the particle velocity. $A_{p, i}$ and $C_{d}$ are the projection area and drag force coefficient of the particle in Equation (6), respectively. $C_{d}$ is acquired by the Morsi-Alexander model, which is suitable for smooth spherical particles:

$$
C_{d}=a_{1}+\frac{a_{2}}{\operatorname{Re}_{\mathrm{p}, i}}+\frac{a_{3}}{\operatorname{Re}_{\mathrm{p}, i}^{2}}
$$

where $\operatorname{Re}_{\mathrm{p}}$ is the relative Reynolds number, which is defined by $\operatorname{Re}_{\mathrm{p}, i}=\rho_{f} d_{p, i}\left|\boldsymbol{v}_{s, i}\right| / \mu$. For the above equation, $d_{p, i}$ is the particle diameter and $\mu$ is the molecular viscosity of the fluid. The constants, $a_{j}(j=1,2,3)$, are given in the literature [25]:

$$
a_{1}, a_{2}, a_{3}=\left\{\begin{array}{lr}
0,24,0 & 0<\operatorname{Re}_{\mathrm{p}}<0.1 \\
3.690,22.73,0.0903 & 0.1<\operatorname{Re}_{\mathrm{p}}<1 \\
1.222,29.1667,-3.8889 & 1<\operatorname{Re}_{\mathrm{p}}<10 \\
0.6167,46.50,-116.67 & 10<\operatorname{Re}_{\mathrm{p}}<100 \\
0.3644,98.33,-2778 & 100<\operatorname{Re}_{\mathrm{p}}<1000 \\
0.357,148.62,-47500 & 1000<\operatorname{Re}_{\mathrm{p}}<5000 \\
0.46,-490.546,-578700 & 5000<\operatorname{Re}_{\mathrm{p}}<10000 \\
0.5191,-1662.5,-5416700 & \operatorname{Re}_{\mathrm{p}} \geq 10000
\end{array}\right.
$$

The solid is treated as a discrete phase. The translational and rotational motions of the spherical particle are able to be described individually by Newton's second law:

$$
\begin{gathered}
m_{p, i} \frac{\mathrm{d} v_{p, i}}{\mathrm{~d} t}=f_{f p, i}+f_{c, i}+m_{p, i} \mathrm{~g} \\
I_{p, i} \frac{\mathrm{d} \boldsymbol{\omega}_{p, i}}{\mathrm{~d} t}=\boldsymbol{M}_{c, i}
\end{gathered}
$$

where $f_{c, i}$ is the interactions of particle-particle and particle-wall, which is the sum of the contact forces $f_{c m}$ :

$$
f_{c, i}=\sum_{\text {contacts }} f_{c m}
$$

Here, $\boldsymbol{I}_{p, i}$ is the moment of inertia of the particle; $\boldsymbol{\omega}_{p, i}$ is the angular velocity of the particle. $\boldsymbol{M}_{c, i}$ is the total torque of contact forces in Equation (10):

$$
\boldsymbol{M}_{c, i}=\sum_{\text {contacts }}\left(\boldsymbol{r}_{c} \times \boldsymbol{F}_{c m}+\boldsymbol{M}_{c m}\right)
$$

Here, $\boldsymbol{r}_{c}$ is the position vector from the center of mass to the point of contact; $\boldsymbol{M}_{c m}$ is the moment acting on the particle due to rolling resistance. 


\subsection{Numerical Method}

Fluid was normal-temperature water, and the solid volume concentration was $5 \%$ at the position of the pump inlet. The particles were spherical with a diameter of $10 \mathrm{~mm}$. The contact forces $\left(f_{c m}\right)$ were solved by the Hertz-Mindlin slip-free contact model [26], and related parameters are listed in Table 3. The material of the pump body was aluminum alloy, and the material of the particles was artificial nodules. The particle material properties were as follows: Poisson's ratio was 0.4 , shear modulus was $21.3 \mathrm{Mpa}$, and density was $2000 \mathrm{~kg} / \mathrm{m}^{3}$.

Table 3. Solid interaction parameters.

\begin{tabular}{cccc}
\hline Interaction of Object & Recovery Factor & $\begin{array}{c}\text { Coefficient of } \\
\text { Static Friction }\end{array}$ & $\begin{array}{c}\text { Coefficient of } \\
\text { Rolling Friction }\end{array}$ \\
\hline Particle-particle & 0.44 & 0.27 & 0.01 \\
Pump-particle & 0.5 & 0.15 & 0.01 \\
\hline
\end{tabular}

Fluent and Engineers' Discrete Element Method (EDEM) software coupling was used for transient calculation. EDEM is a software for bulk material simulation. The fluid time step is set to $0.0001 \mathrm{~s}$, which is about $1^{\circ}$ of the impeller rotations. The particle time step is set to $0.00005 \mathrm{~s}$, which is about $15 \%$ of the Rayleigh time step. The shear stress transport (SST) k- $\omega$ model (Menter's Shear Stress Transport turbulence model) is used in this study. The impeller was in a rotating coordinate system, and the bowl diffuser was in a stationary coordinate system. The length $(338 \mathrm{~mm})$ of the inlet extension section was 2.5 times the inlet diameter $(135 \mathrm{~mm})$ of the impeller. The inlet boundary adopts the mass flow inlet. It is assumed that the flow at the inlet is axisymmetric and non-rotation. The length $(343 \mathrm{~mm})$ of the outlet extension section was 2.5 times the outlet diameter $(137 \mathrm{~mm})$ of the bowl diffuser. The outlet boundary adopts the free outlet boundary. The wall adopts the no-slip boundary condition, and the standard wall function is used near the wall.

If the particle volume is larger than the cell volume in the CFD-DEM calculation, non-physical and non-smooth results may occur, which causes numerical instability. Therefore, the cell size should be larger than the particle diameter [27]. Fine mesh was not available due to the large particle diameter $(10 \mathrm{~mm})$. Still, the grids of the area where particles cannot enter should be densified.

According to the above cell size limits, four grids with different scales were constructed. Table 4 provides the grid properties for simulation of water conditions under actual operating points. $\varepsilon_{H}$ and $\varepsilon_{E}$ are the relative errors for the head and efficiency between the numerical and experimental results. Grid independence analysis indicated that the calculation accuracy is no longer significantly increased when the grid scale is around 700,000. Therefore, grid 3 (shown in Figure 3) was adopted. The final grid scale was 722,614, of which the bowl diffuser cell count was 43,670 and the impeller cell count was 30,916.

Table 4. Results from the mesh independence analysis.

\begin{tabular}{cccccc}
\hline Grid Number & Cell & Head $(\mathbf{m})$ & $\mathcal{\varepsilon}_{\boldsymbol{H}} \mathbf{( \% )}$ & Efficiency $\mathbf{( \% )}$ & $\mathcal{\varepsilon}_{\boldsymbol{E}} \mathbf{( \% )}$ \\
\hline 1 & 484,378 & 37.656 & 4.60 & 71.418 & 4.95 \\
2 & 621,314 & 37.757 & 4.88 & 72.130 & 4.00 \\
3 & 722,614 & 37.659 & 4.61 & 72.678 & 3.27 \\
4 & 819,244 & 37.506 & 4.18 & 71.738 & 4.53 \\
Experiment & & 36 & & 75.138 & \\
\hline
\end{tabular}



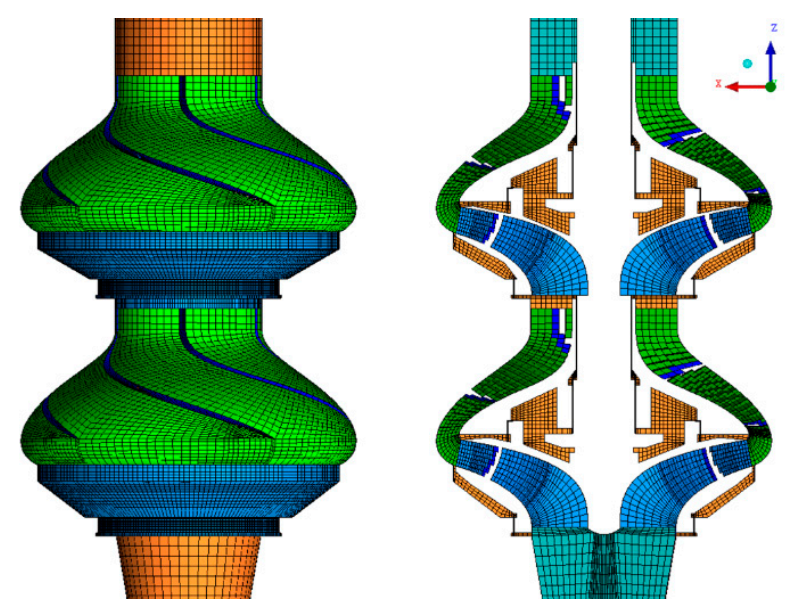

Figure 3. The calculation grid of the slurry transport pump.

\section{Experiment and Validation}

\subsection{Experimental Device}

The experimental system shown in Figure 4 consists of circulating piping (green arrow) and pressure piping (orange arrow). The circulating piping is used to test the ability and reliability of continuous slurry conveying in a slurry transport pump. Particles from the particle tank (11) pass through the feeding particles machine (1) uniform rate into the pipeline, and then through the pump (3) into the outlet pipeline. Particles and water return to the particle tank. Water enters the water tank (13) through the filter (12) and then returns to the circulation pipe line through the gate valve (17). When circulating piping is used, it is difficult to change the working condition of the pump. Due to the presence of particles, the resistance characteristics of the pipeline cannot be adjusted by the valve (6) at the pump outlet. Therefore, the pressure piping is added on this basis. The three-way valve can be adjusted so that particles and water no longer enter the particle tank (11) but the solid-liquid separation tank (16). Particles are left in the tank (16) and no longer participate in the circulation, while water enters the water tank (13) through the filter (15) and ball valve (14). The operating condition of the pump is regulated by the ball valve (14). Particles are still replenished from the particle tank (11). The photos of the experimental system are shown in Figure 5.

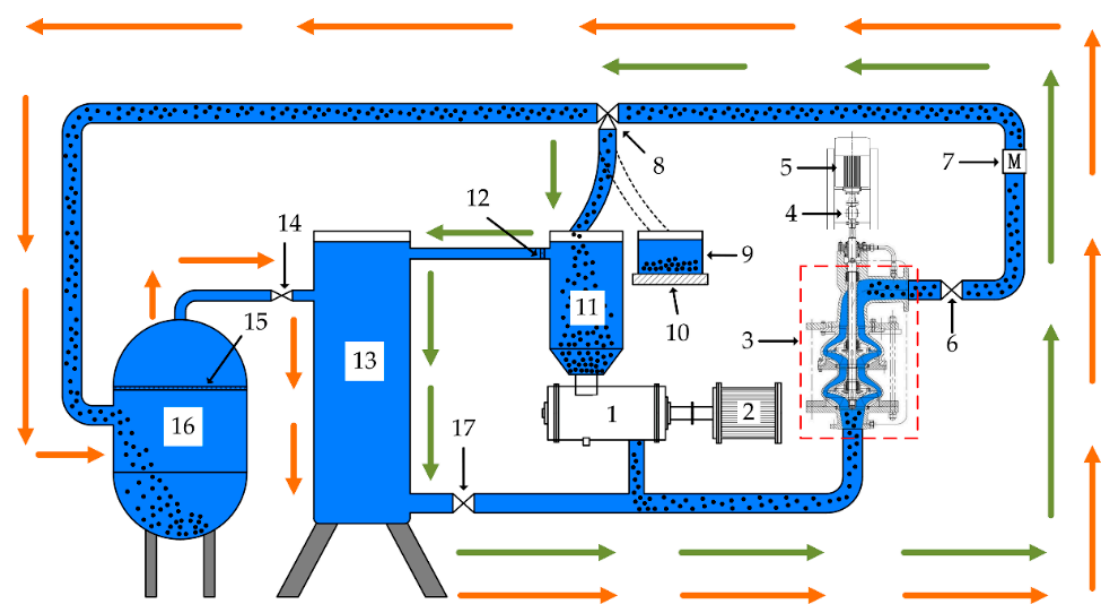

Figure 4. Schematic diagram of slurry transport system: (1) Feeding particles machine, (2) Motor 1, (3) Slurry transport pump, (4) Torque meter, (5) Motor 2, (6) Butterfly valve, (7) Electromagnetic flowmeter, (8) Three-way valve, (9) Calibration box, (10) Platform scale, (11) Particle tank, (12) Filter, (13) Water tank, (14) Ball valve, (15) Filter, (16) Solid-liquid separation tank, and (17) Gate valve. 


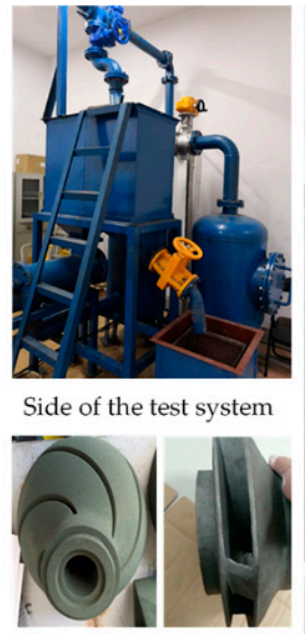

Bowl diffuser Impeller

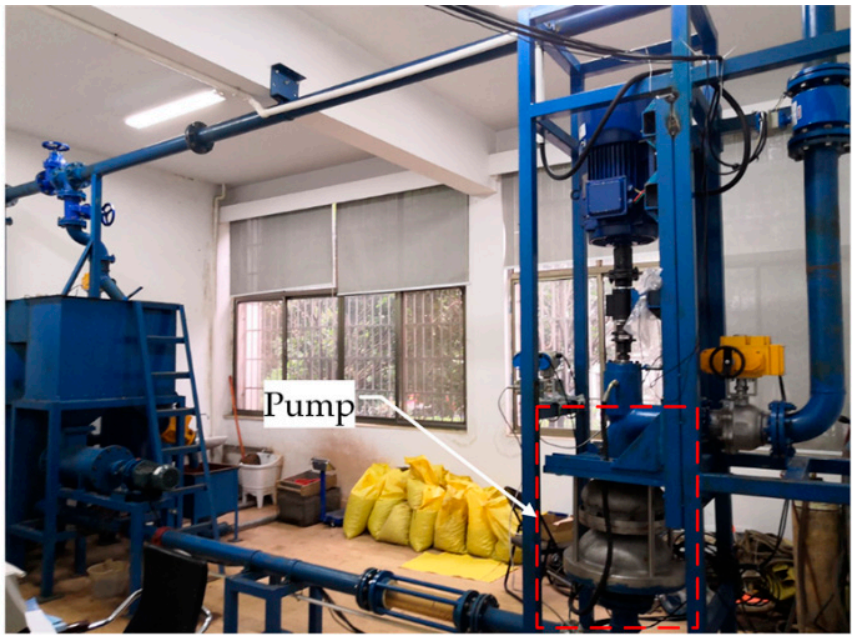

Overall view of the test system

Figure 5. Test system of slurry transport.

A calibration box (9) and platform scale (10) are used to measure the solid-phase concentration in the pipeline by the weighing method. The particles are artificial nodules with a diameter of $10 \mathrm{~mm}$. During the experiment, the volume concentration was controlled to $5 \%$ by adjusting the speed of Motor (2).

The flow rate was measured by an electromagnetic flowmeter with the accuracy of $\pm 0.3 \%$ and the range of $0.5 \sim 10 \mathrm{~m} / \mathrm{s}$. The pump inlet and outlet pressures were measured by pressure gauges with an accuracy of $\pm 0.2 \%$ and a range of $-250 \sim 250 \mathrm{Kpa}$. Torque was measured by a torque meter with an accuracy of $\pm 0.4 \%$ and a range of $1 \sim 100 \mathrm{~N} \cdot \mathrm{m}$. The first-order uncertainty analysis was conducted using the constant odds combination method. The uncertainty of flow rate, head, power, and efficiency is $\pm 1.11 \%, \pm 1.67 \%, \pm 1.11 \%$, and $\pm 2.29 \%$, respectively.

\subsection{Experimental Result}

In order to prevent the coarse particles from blocking the pump, the flow amplification design method was used in the design of slurry transport pump [28]. After the parameter amplification, the width of the impeller increases significantly, and the specific speed of the pump also increases. High specific speed means that the actual flow rate increases and head reduction. The increase in flow rate will lead to serious deviation between the optimal design condition point and the actual working condition point. As shown in the literature [29], under the actual working point of the slurry transport pump of KSB (a German multinational pumps and valves manufacturer), the flow rate is $500 \mathrm{~m}^{3} / \mathrm{h}$, head is $265 \mathrm{~m}$, rotation speed is $1726 \mathrm{r} / \mathrm{min}$, and the efficiency is about $57 \%$. However, under the optimal efficiency point, the flow rate is about $920 \mathrm{~m}^{3} / \mathrm{h}$, head is $190 \mathrm{~m}$, and efficiency is about $75 \%$, which indicates that the optimal efficiency point of the KSB pump is shifted towards a large flow rate. The same thing happened in our pump. As shown in Figure 6, the optimal efficiency point of the pump under slurry condition moves to $200 \mathrm{~m}^{3} / \mathrm{h}$, and that of water condition moves to $210 \mathrm{~m}^{3} / \mathrm{h}$ under the water condition. The actual working point of the pump is $120 \mathrm{~m}^{3} / \mathrm{h}$.

When the flow rate is small, the calculation and experiment are in good agreement. Under the large flow rate condition, the calculated efficiency value is larger than the experimental result. The difference between the calculated result and the experimental result is calculated at the actual operating point; under the slurry working condition, the head difference is $0.49 \mathrm{~m}$, the shaft power difference is $0.21 \mathrm{kw}$, and the efficiency difference is $2.03 \%$; under the water condition, the head difference is $1.66 \mathrm{~m}$, the shaft power difference is $2.27 \mathrm{kw}$, and the efficiency difference is $2.46 \%$. The calculation error is within the allowable range. 


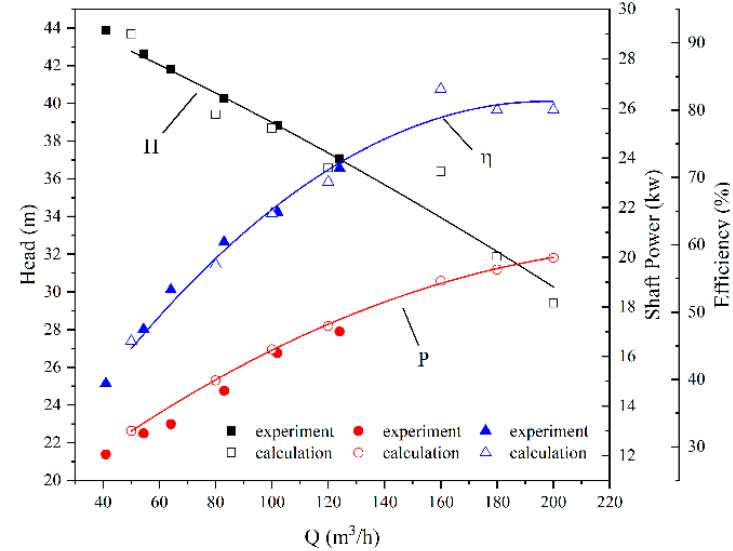

(a)

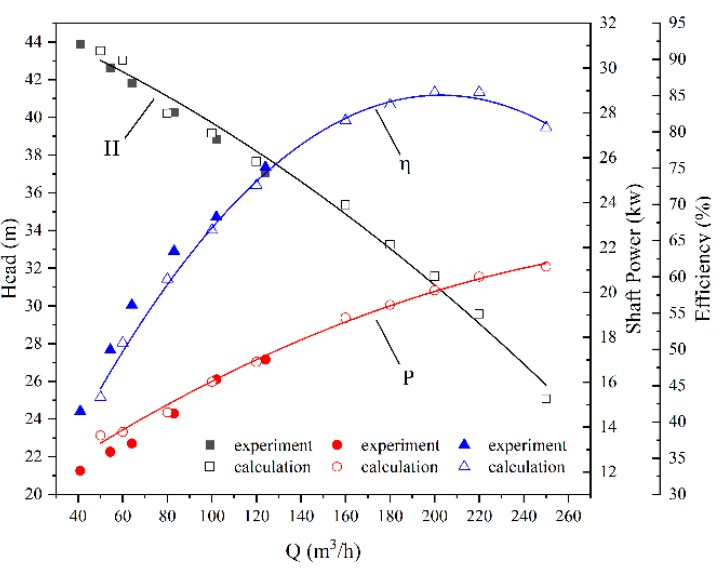

(b)

Figure 6. Performance curve of the slurry transport pump: (a) slurry condition; (b) water condition.

\section{Results and Discussion}

This section only deals with actual working conditions $\left(Q=120 \mathrm{~m}^{3} / \mathrm{h}\right)$. Transient calculation is performed. According to the residual curve and the number of particles, it is judged whether the simulation has reached a steady state. The particle data of 1.2-1.4 $\mathrm{s}$ and flow filed at $1.2 \mathrm{~s}$ are selected as the research object.

\subsection{Flow Features}

The velocity field of fluid is closely related to particle motion. Figure 7 shows the velocity of the fluid on the axial section at $1.2 \mathrm{~s}$. The influence of pump cavity and balance hole leakage on velocity field can be seen. First of all, the situation inside the impeller is concerned. The backflow velocity of the front cavity is higher than that of the fluid entering the impeller from the inlet. The backflow develops downstream. At the same time, the backflow squeezes the fluid entering the inlet, causing it to deflect toward the hub. The dotted line in Figure 7 indicates the position of the balance hole. The backflow velocity of the balance hole is also higher than that of the fluid entering the inlet. The backflow velocity in the front cavity of the second stage is higher than that of the first stage, and the squeezing effect on the fluid entering the inlet is more obvious. This leads to interference with the backflow of the balance hole.

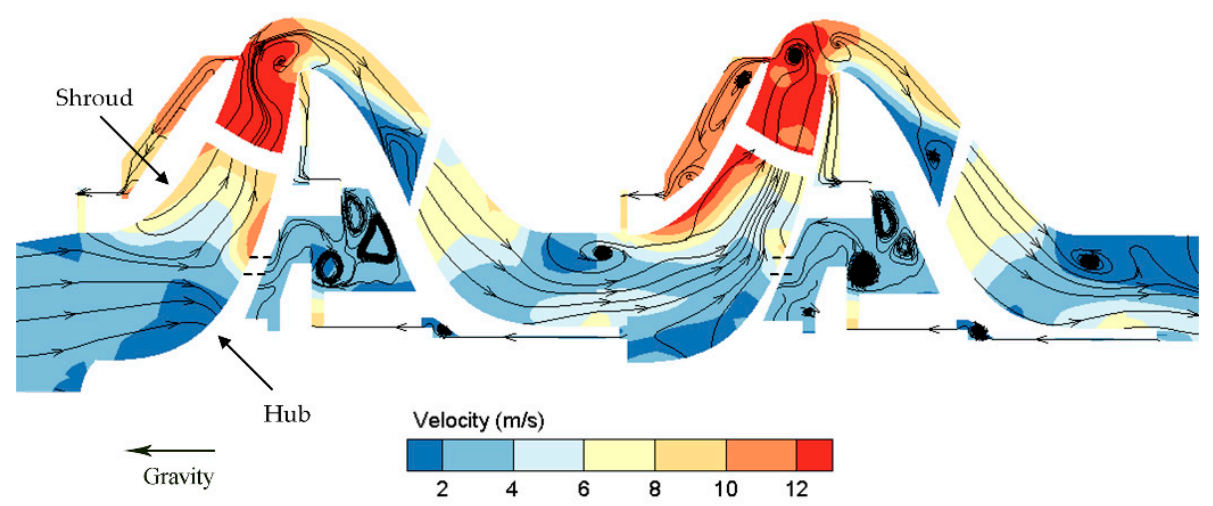

Figure 7. Velocity of continuous phase in shaft section at $1.2 \mathrm{~s}$.

The velocity field of the bowl diffuser is not significantly affected by leakage. The main characteristic of the bowl diffuser is that the kinetic energy of the fluid is gradually converted into pressure energy. Figure 8 shows the velocity distribution on the spanwise surface at $1.2 \mathrm{~s}$. It can be seen that the 
circumferential velocity of fluid increases in the impeller, but the axial velocity does not change much. The fluid entering the bowl diffuser concentrates on the suction surface (SS) of the blade under the action of centrifugal force, which results in low circumferential and axial velocity of the fluid near the pressure surface (PS). A vortex forms in this low-velocity region. The circumferential velocity of the fluid near the suction surface decreases and the axial velocity increases. The axial velocity at the outlet of the second bowl diffuser is slightly higher than that of the first guide blade.

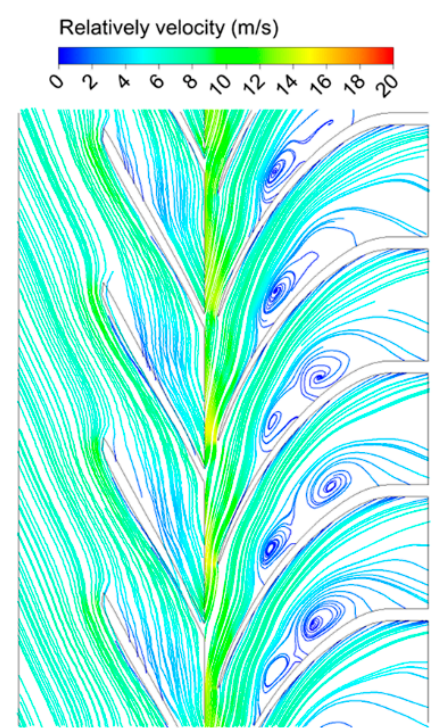

Impeller

Bowl diffuser

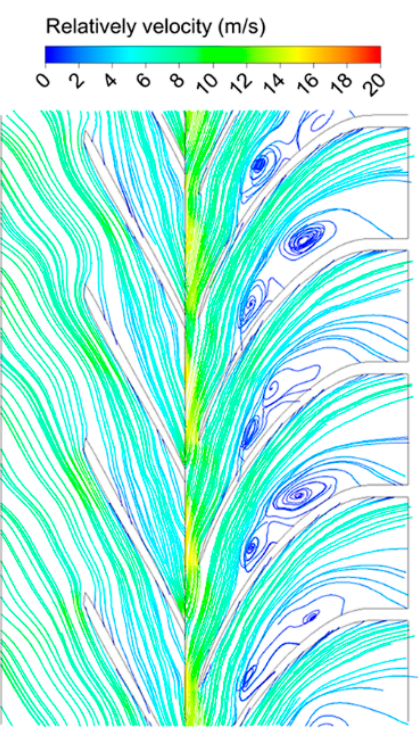

Impeller

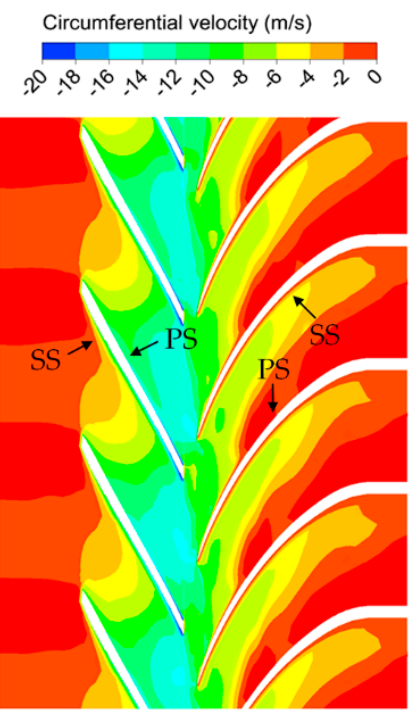

Span $=0.5$

(a)

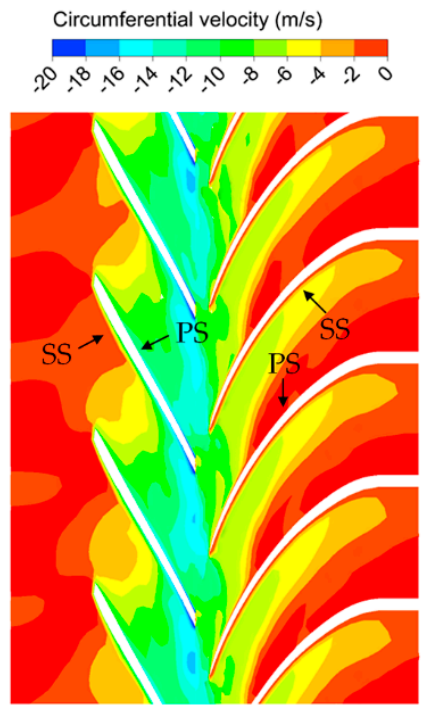

Span $=0.5$

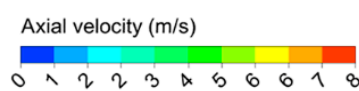

Axial velocity $(\mathrm{m} / \mathrm{s})$

$01223 \times 56610$

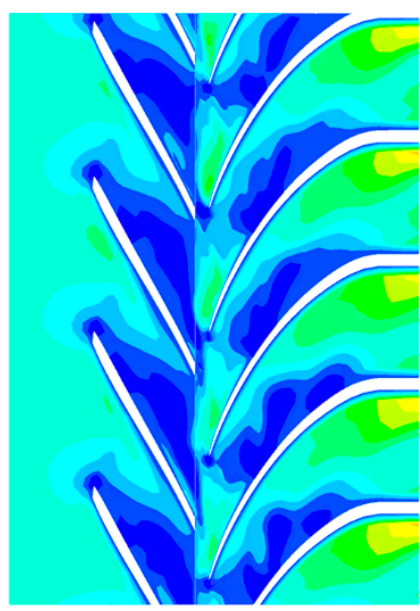

Axial velocity $(\mathrm{m} / \mathrm{s})$
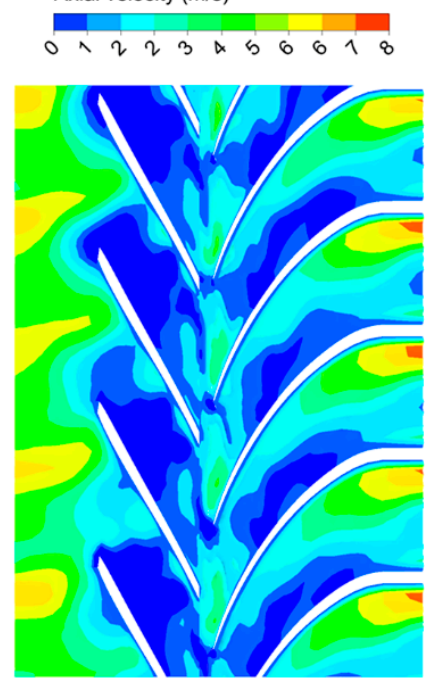

(b)

Figure 8. Relatively velocity, circumferential velocity, and axial velocity of continuous phase on the spanwise surface at $1.2 \mathrm{~s}$ : (a) the first stage; (b) the second stage.

The blade number of the impeller is four, and that of the bowl diffuser is five. The impeller is a rotating part and the bowl diffuser is a stationary part. So, there is dynamic and static interference between them. The position relationship between each blade of the impeller and blades of the bowl diffuser is different at any moment. The flow is not rotationally symmetric in the transition region 
connecting the impeller to the guide blade. Therefore, there are differences in different flow passages. This article focuses on particle motion. Further research on interference will be conducted in the future.

\subsection{Distribution and Motion of Patticles}

The anti-blocking performance and reliability of the slurry transport pump are closely related to the distribution and motion of particle groups. Particle motion in the pump is well simulated by the CFD-DEM model. In this section, the spatial distribution and velocity changes of particle groups in the entire pump are described. Then, particle motion in the main hydraulic components is studied in detail.

\subsubsection{Characteristics of Particle Swarm}

The particles pass through the super-long riser in the deep-ocean mining system and reach a relatively stable state at the pump inlet. Therefore, it can be assumed that the particles reach a stable velocity at the pump inlet and the position distribution of particle groups in the inlet plane is random. The influence of external excitation is ignored in our numerical simulation.

Figure 9 shows the distribution and velocities of the particles within the entire pump. Particles' states between the first and second stages are similar. In one stage, particles accumulate at the impeller inlet and their velocities are reduced to the minimum. Particles follow the fluid into the impeller passage and their velocities increase with the increase in their radial position. The particles reach their maximum velocities at the outlet of the impeller. Before particles enter the bowl diffuser passage, they tend to collide with the wall and their velocities decrease obviously. When passing through the guide vane passage, the particles move towards the outlet by closing to the suction surface of bowl diffuser. In the process, the velocity changes of the particles are not obvious.

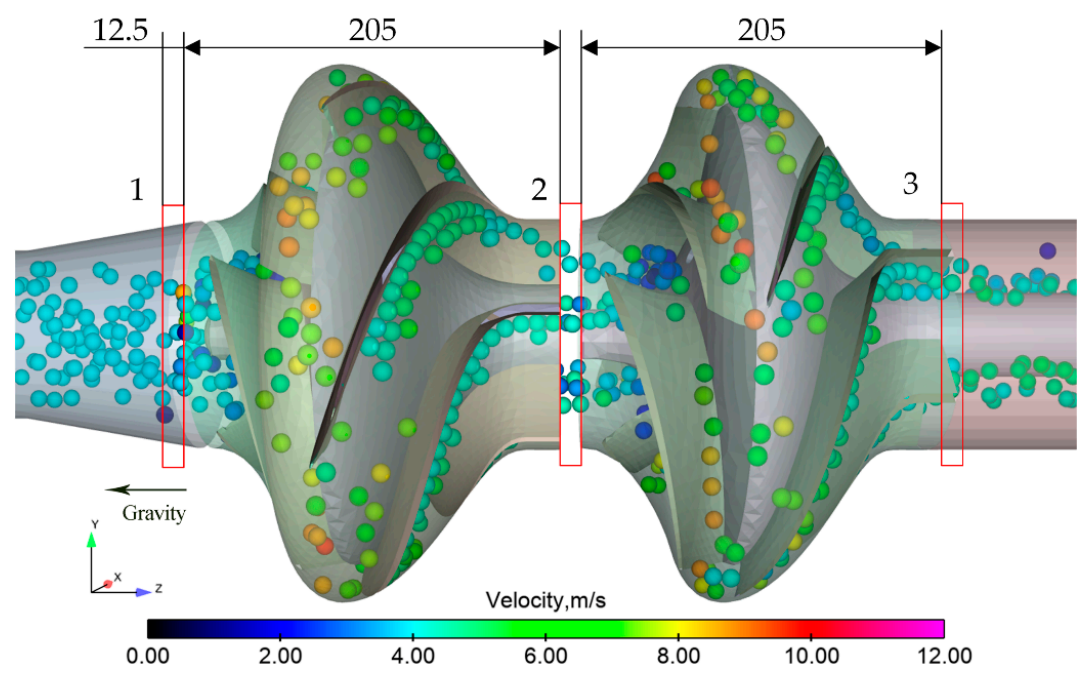

Figure 9. Distribution and velocity of particle groups in the entire slurry transport pump at $1.2 \mathrm{~s}$.

In one stage, the number of particles may affect the performance of this stage, and the average kinetic energy of particles in the bowl diffuser outlet plane is the final reflection of particle swarm motion in this stage. The axial velocity of particles is dominant at the outlet of bowl diffuser. The cylinder area of the same size is divided in the corresponding position according to the size marked in Figure 9. These cylinders replace the inlet and outlet planes of one stage. Figure 10a shows the statistics of the average kinetic energy $K_{j}$ of particles in each cylinder area within 1.2-1.4 s, which is calculated by:

$$
K_{j}=\frac{\sum_{i=1}^{N} K_{j i}}{N_{j}}(j=1,2,3)
$$


where $i$ is the particle index, $K_{j}$ is the average kinetic energy of particles, $K_{i j}$ is the kinetic energy of the particle $i$, and $N_{j}$ is the total number of particles passing through the $j$ area within 1.2-1.4 s. The average kinetic energy of the particle swarm increases by about $0.00758 \mathrm{~J}$ through the first stage, but only increases by about $0.00355 \mathrm{~J}$ through the second stage. From the analysis in the next section, we see that most of the energy obtained by the particles from the impeller is lost in the collision. This makes the outlet velocity of the bowl diffuser the most important factor affecting $K_{1}$ and $K_{2}$.

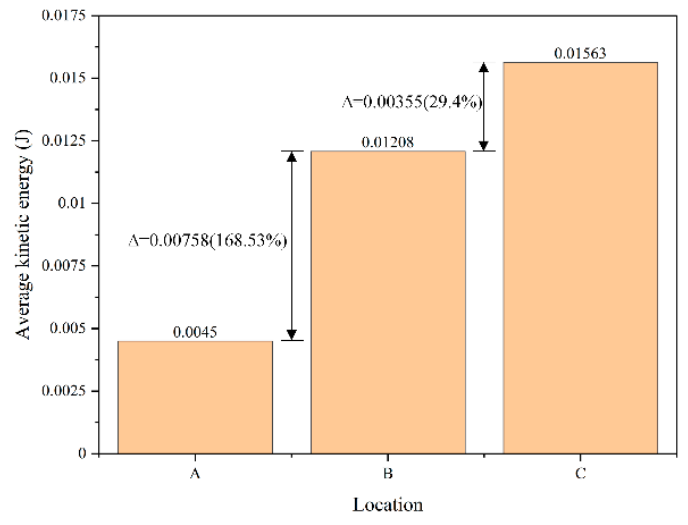

(a)

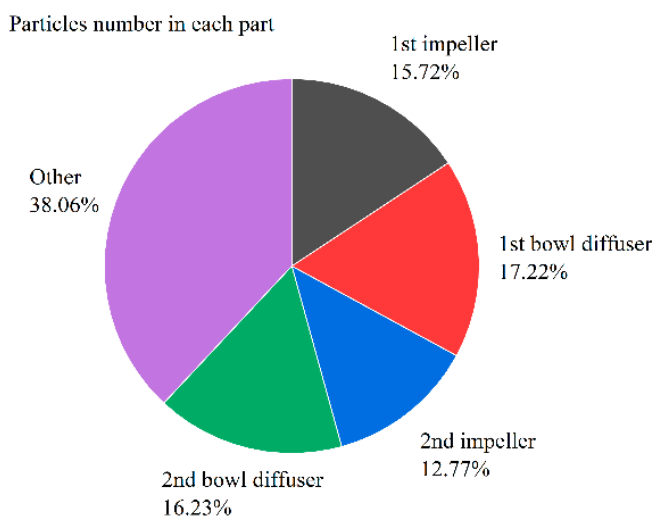

(b)

Figure 10. (a) Average kinetic energy of particles at the inlet of the first stage, the transition area between stages, and the outlet of the second stage; $(\mathbf{b})$ the percentage of the particle number.

Figure 10b compares the percentage of particle count in each hydraulic component, showing that there are more particles in the first stage than in the second. The number of particles in the impeller differs by $2.95 \%$ and that in the guide vane differs by $0.99 \%$. At the beginning of the simulation, many particles crowded into the first impeller and piled up near the inlet. The collision between particles was frequent and it was difficult for particles to leave the accumulation region. But only a few particles entered the second impeller, and the accumulation phenomenon was alleviated. Meanwhile, the axial velocity of the fluid in the second bowl diffuser was larger, which reduced the passing time of particles.

\subsubsection{Particle Motion in Impeller}

Figure 11 shows the velocity and distribution of particles in the impeller at $1.2 \mathrm{~s}$. The particles are clearly divided into two parts by their velocity. The surface formed by rotating the leading edge of the impeller around the central axis is taken as the "interface". The impeller is divided into two regions with the interface. The region with particles of low velocity is called the slowing region, and the region with particles whose velocity is increasing is called the accelerating region. Particle distribution is concentrated in the slowing region and is sparse in accelerating region. After the fluid entering the impeller, the flow direction changes (from axial to radial), while the flow follower of coarse particles is poor, and the particles generally maintain axial movement. Then, particles collide with the impeller hub, which leads to slowing of particles. Finally, the particles are crowded in the slowing region.

In order to study the motion of particles in the accelerating region, all particles in the slowing region at $1.2 \mathrm{~s}$ were selected as samples. Because the particles crowd in the slowing region, the particles tend to collide with the leading edge of the blade and, thus, have a high velocity. After several collisions, the velocities of different particles near the interface vary greatly. The velocity difference will further lead to the difference in the motion of particles in accelerating region. In the first stage, the accumulation of particles in the slowing region is more serious than that in the second stage. This makes it easier for the first-stage particles to collide with the leading edge of blades. 


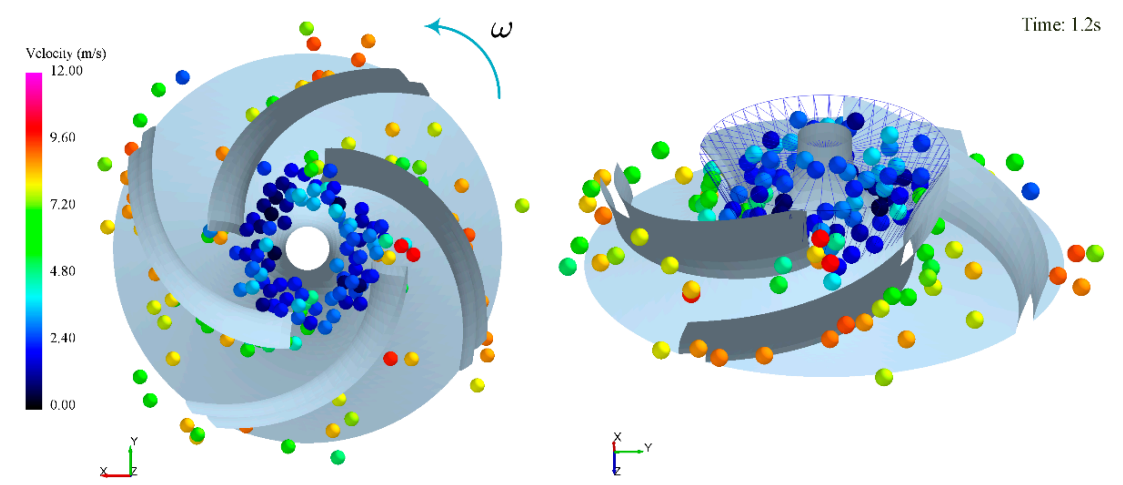

(a)
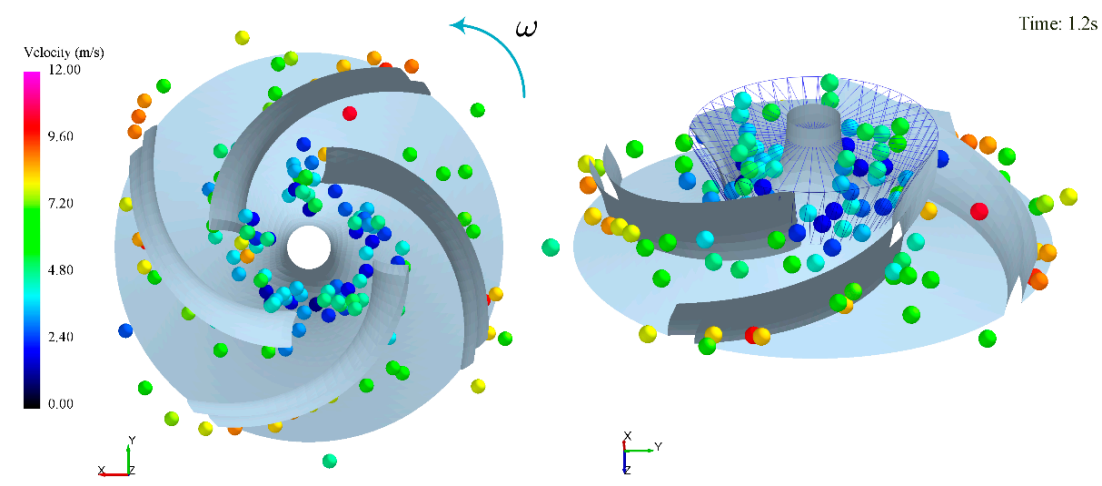

(b)

Figure 11. Color indicates the velocity of particles: (a) particles in the first stage impeller; (b) particles in the second stage impeller.

The velocity at which a particle passes through the interface influences its subsequent motion. The velocity direction difference of particles is not obvious when they pass through the interface, so we focus on the value of velocity. The velocity $V_{\text {in }}$ in Figure 12 refers to the velocity of a particle after its last pass through the interface. The collision number refers to the number of collisions between a particle and the impeller blades after it passes through the interface for the last time. As shown in Figure 12, particles in the accelerating region are divided into five parts according to their motion characteristics. Part 1 and Part 2 together are called low-velocity particles. Overall, $51.76 \%$ of the first-stage particles and $84.09 \%$ of the second-stage particles are low-velocity particles.

Figure 13 is the curve of the velocity and the velocity first-order difference varying with the radial position for single particle. The legend is the ID of particles. One crest of the velocity first-order difference represents a collision. $V_{\text {in }}$ of Part 1 is low. These particles collide with the blade several times and their velocity increases in a step-like manner. Part 2 is more complex, with low $V_{\text {in }}$ but no collisions with the blades. Part 1 accounts for $44.23 \%$ and part 2 for $21.15 \%$ of the total sample. $V_{\text {in }}$ of Parts 3 and 4 is large. Part 3 avoids collision with the blades, while Part 4 only collides with the blades near the outlet of the impeller. Except for the curve of the head and tail, their velocity changes are similar. Part 5 is at high velocity, passing through the interface, but collides with other particles after entering the accelerating region. The particle velocity changes significantly and finally presents a situation like Part 1 . To sum up, if the particle velocity is low after passing through the interface, it is more likely to collide with the blades.

As shown in Figure 13, whether particles collide with the blade will lead to a huge velocity difference in the accelerating region, which will further affect the velocity of particles at the outlet of the impeller. The particles are divided into colliding and non-colliding groups. Figure 14 is the distribution of radial velocity and circumferential velocity when particles are at the impeller outlet. The results show that the radial velocity of particles in the colliding group is concentrated in the 
high-velocity interval, and the distribution difference of circumferential velocity between the two groups is not obvious. Particles in the colliding group of the first stage accounted for $51.67 \%$ of the first-stage sample, and those of the second stage accounted for $63.64 \%$ of the second-stage sample. Therefore, the probability that second-stage particles will obtain higher radial velocity when leaving the impeller is slightly greater than that of the first-stage particles. Most of the particles will collide with the shroud of bowl diffuser after leaving the impeller. As shown in Figure 15a, radial velocity loses a lot in this collision, while circumferential velocity only loses a little. In summary, collision with the blade may cause the particles to have a greater radial velocity when leaving the impeller.

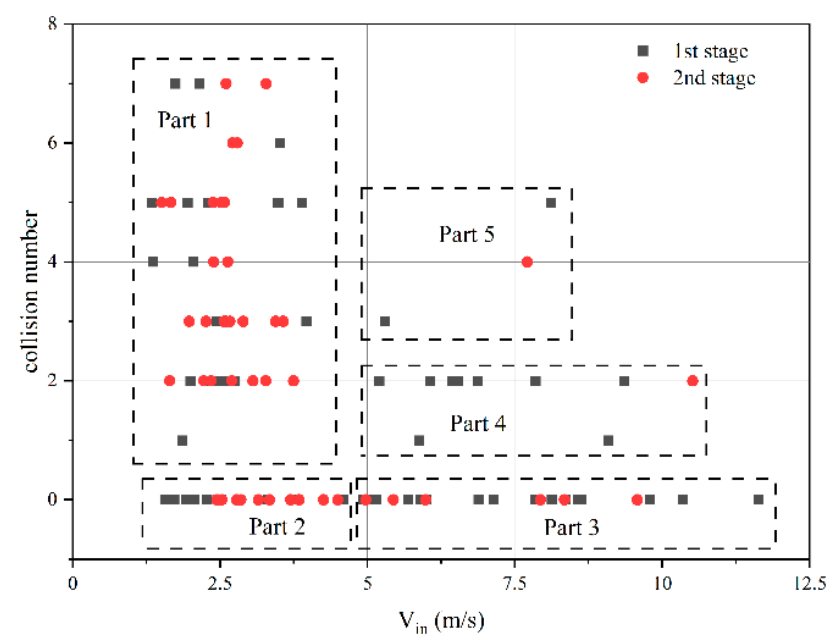

Figure 12. $V_{\text {in }}$ refers to the velocity of a particle after its last pass through the interface, and collision number refers to the number of collisions between a particle and the impeller blade after its last pass through the interface.

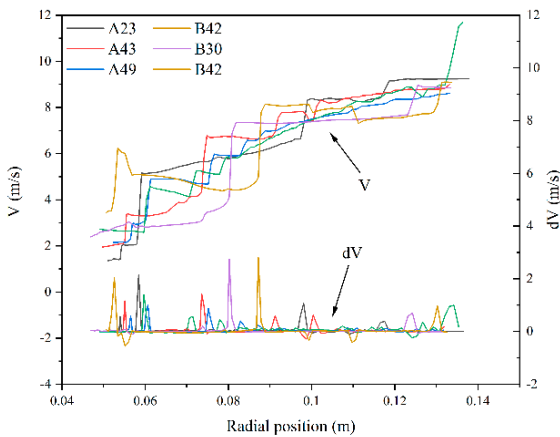

(a)

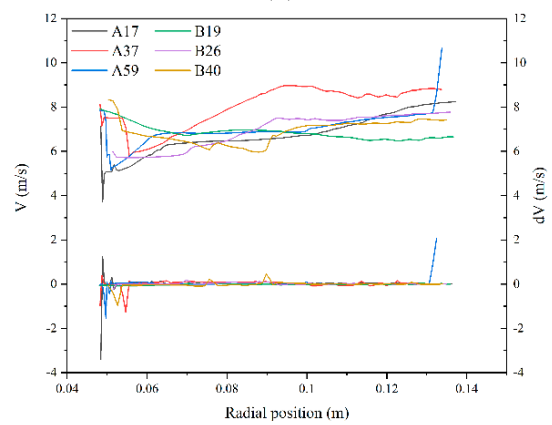

(c)

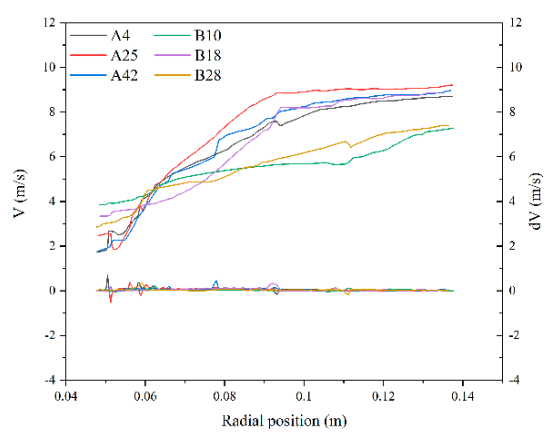

(b)

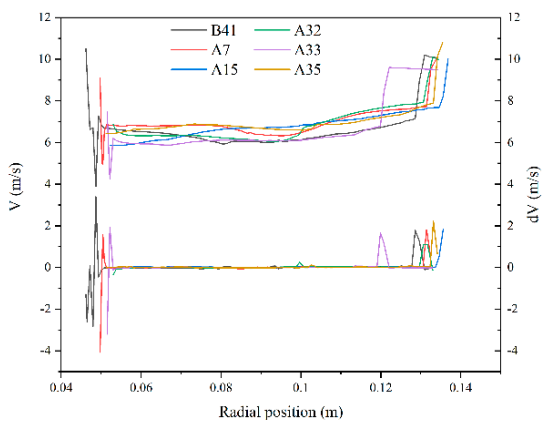

(d)

Figure 13. Cont. 


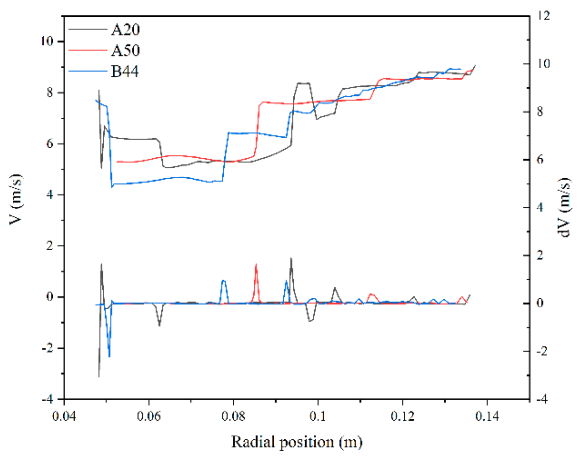

(e)

Figure 13. Letter and numbers form the ID of the particle. " $\mathrm{A}$ " represents the first stage and " $\mathrm{B}$ " represents the second stage. The velocity and the first-order difference of the velocity vary with the radial position: (a) Part 1; (b) Part 2; (c) Part 3; (d) Part 4; (e) Part 5.

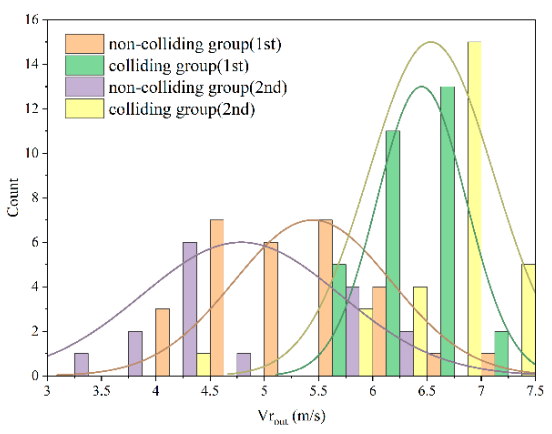

(a)

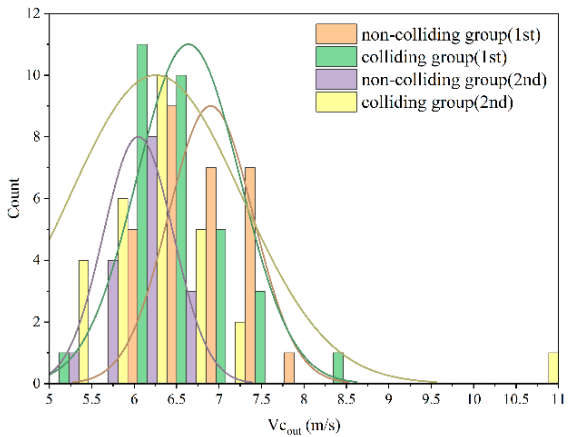

(b)

Figure 14. The radial and circumferential velocities of the particles: (a) distribution of radial velocity $V r_{\text {out }} ;$ (b) distribution of radial velocity $V c_{\text {out }}$.

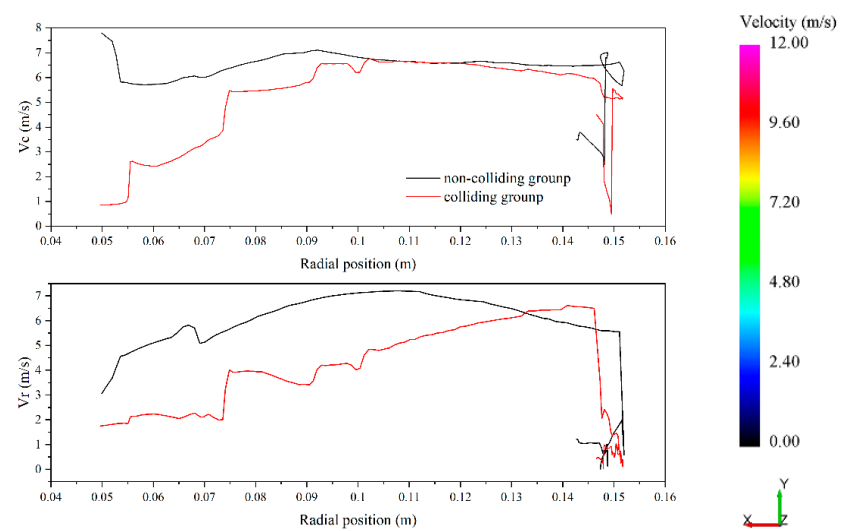

(a)

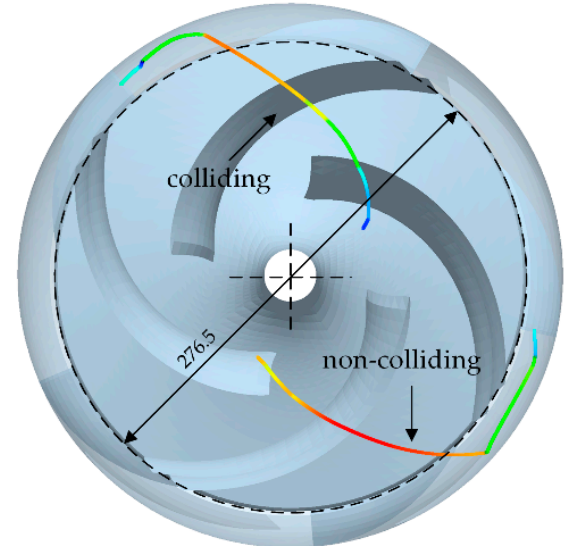

(b)

Figure 15. (a) Circumferential and radial velocity of two selected particles in the first stage; (b) particle trajectory in the first stage.

\subsubsection{Particle Motion in Bowl Diffuser}

Figure 16 shows the motion of particles in the bowl diffuser. Most of the particles have similar motion states. There is little difference between the two stages. Particles are concentrated near the shroud of the bowl diffuser and close to the suction surface of the blades. Any particle can be selected 
to plot its trajectory. The trajectory of the particle is a broken line, and the particles experience many collisions and bounces on the suction surface.
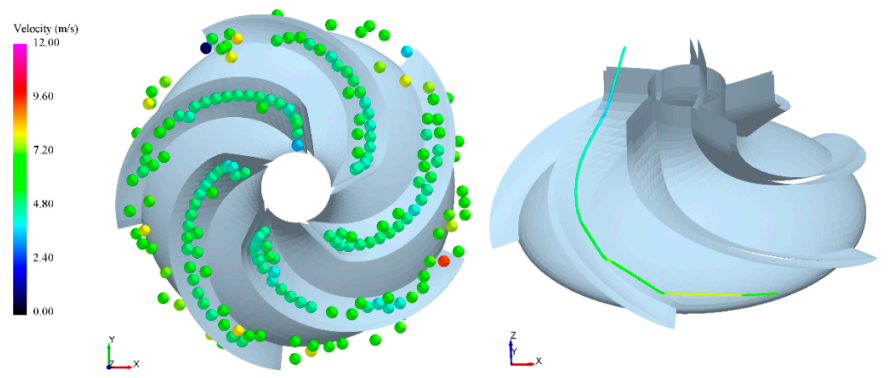

(a)
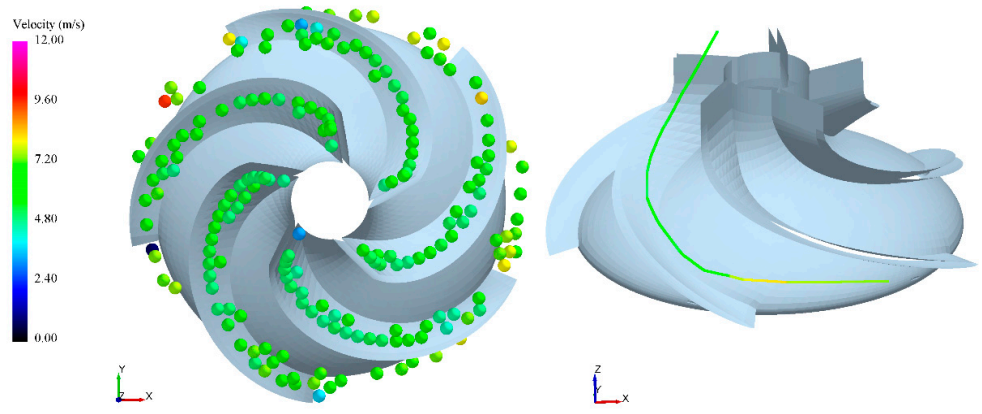

(b)

Figure 16. The left picture shows the distribution of particles at $1.2 \mathrm{~s}$, and the right picture shows the trajectory of a certain particle. Color indicates the velocity of particles: (a) particles in the first-stage bowl diffuser; (b) particles in the second-stage bowl diffuser.

In the bowl diffuser passage, the axial velocity of the fluid increases gradually from the inlet to the outlet (Figure 8), while the circumferential velocity decreases from a large value at the inlet to a small value at the outlet. The velocity of the fluid decreases gradually to achieve the conversion of kinetic energy to pressure energy. Coarse particles have poor flow followability and their motion state will not change rapidly with the change of fluid velocity. So, the particles deviate from the direction of the fluid under centrifugal force and concentrate outwards. After entering the bowl diffuser, the axial velocity of particles is lower than that of the fluid. Thus, the axial drag force of fluid accelerates the particles. Figure 17 shows that the axial and circumferential velocities of two particles vary with their axial position. The particles experience three motion periods in the bowl diffusers.

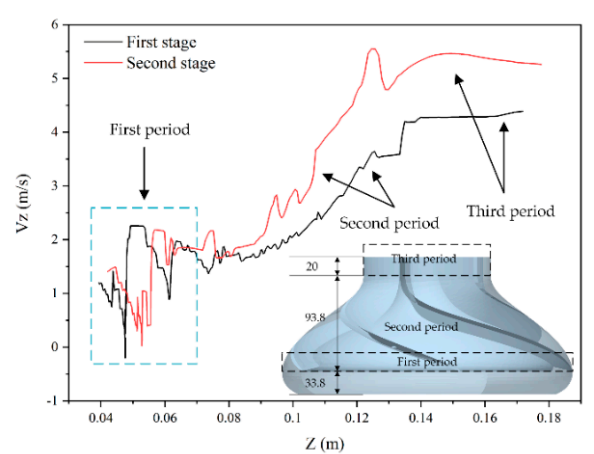

(a)

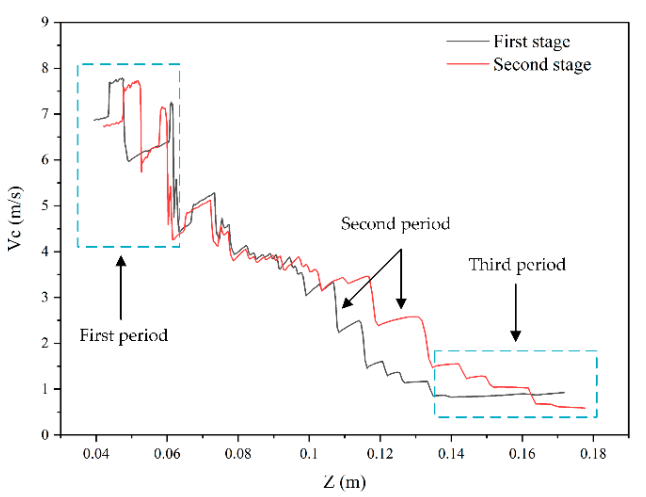

(b)

Figure 17. There are differences between different particles, and the dotted box only indicates the approximate location: (a) axial velocity $V_{z}$ of particles in the bowl diffuser; (b) circumferential velocity $V_{c}$ of particles in the bowl diffuser. 
The first period starts from the particle leaving the transition area to the end of particle contacting with the blade. Since the axial velocity of the fluid is small when it enters the bowl diffuser, the axial drag force provided by the fluid to the particles is insufficient to offset the gravity. This causes the particles' axial velocity to decrease at the beginning. Then, the particles collide with the blades. The axial velocity step increases while the circumferential velocity step decreases. In the second period, the particles move along the suction surface toward the outlet and the axial velocity increases gradually, while the circumferential velocity decreases gradually. The velocity curves are serrated, indicating that the particles are frequently colliding with the blades. In the third period, the particles leave the flow passage with stable axial and circumferential velocity. The circumferential velocity of the particles reduces to close to 0 .

Considering the velocity change of particles, it can be inferred that collision between particles and blades in the bowl diffuser passage not only leads to energy loss but also gradually transforms the circumferential velocity of particles into axial velocity.

\section{Conclusions}

The characteristics of particle swarm in a two-stage slurry transport pump and the motion details of particles in the main hydraulic components were studied at the actual working point. The results show that the number of particles in the first stage is higher than that in the second stage. The average kinetic energy of particles before entering the pump is $4.5 \times 10^{-3} \mathrm{~J}$, which increases by $7.58 \times 10^{-3} \mathrm{~J}$ after passing through the first stage, while it only increases by $3.55 \times 10^{-3} \mathrm{~J}$ through the second stage. The particles in the impeller are divided into two groups according to whether they collide with the blade. Particles accumulate in the area of the impeller inlet. If the velocity of a particle is large when it leaves the accumulation area, the possibility of collision with the blade can be reduced. The radial velocity of particles in the collision group is concentrated in the high velocity interval when they leave the impeller, while that in the non-collision group is just the opposite. The movement of particles in the bowl diffuser is divided into three periods. In the most important second period, the axial velocity of particles increases and the circumferential velocity decreases. The particles experience many collisions and bounces on the blade surface of the bowl diffuser. It can be inferred that the collision between particles and blades in the bowl diffuser not only leads to energy loss but also gradually transforms the circumferential velocity of particles into axial velocity.

Author Contributions: Conceptualization, X.S.; Funding acquisition, X.S. and Y.L.; Investigation, Z.T.; Project administration, Z.Z.; Resources, K.M. and P.B.; Writing-original draft, Z.T.; Writing-review \& editing, X.S. and Y.L. All authors have read and agreed to the published version of the manuscript.

Funding: This research was funded by NSFC program NO. 51706206, 51976197, Zhejiang public welfare projects NO. LGF19E060001, Starting Foundation of Zhejiang Sci-Tech University NO. 16022180-Y. and Postdoctoral Sustentation Fund NO. 2017M622561.

Conflicts of Interest: The authors declare no conflict of interest.

\section{References}

1. Hein, J.R.; Mizell, K.; Koschinsky, A.; Conrad, T.A. Deep-ocean mineral deposits as a source of critical metals for high- and green-technology applications: Comparison with land-based resources. Ore Geol. Rev. 2013, 51, 1-14. [CrossRef]

2. Glasby, G.P.; Li, J.; Sun, Z. Deep-Sea Nodules and Co-rich Mn Crusts. Mar. GeoResour. Geotechnol. 2014, 33, 72-78. [CrossRef]

3. Sharma, R. Environmental Issues of Deep-Sea Mining. Procedia Earth Planet. Sci. 2015, 11, 204-211. [CrossRef]

4. Frimanslund, E.K.T. Feasibility of Deep-Sea Mining Operation within Norwegian Jurisdiction. Master's Thesis, Norwegian University of Science and Technology, Trondheim, Norwegian, 2016. 
5. Deepak, C.R.; Shajahan, M.A.; Atmanand, M.A.; Annamalai, K.; Jeyamani, R.; Ravindran, M.; Schulte, E.; Handschuh, R.; Panthel, J.; Grebe, H.; et al. Developmental Tests On the Underwater Mining System Using Flexible Riser Concept. In Proceedings of the Fourth ISOPE Ocean Mining Symposium, Szczecin, Poland, 23-27 September 2001.

6. Pougatch, K.; Salcudean, M. Numerical modelling of deep sea air-lift. Ocean Eng. 2008, 35, 1173-1182. [CrossRef]

7. Liu, S.; Yang, N.; Han, Q. Research and development of deep sea mining technology in China. Proc. Int. Conf. Offshore Mech. Arct. Eng. OMAE 2010, 3, 163-169. [CrossRef]

8. Kurushima, M.; Kuriyagawa, M.; Koyama, N.K. Japanese Program for Ikp Seabed Mineral Resources DeveIopmen. In Proceedings of the Offshore Technology Conference, Houston, TX, USA, 1-4 May 1995. [CrossRef]

9. Zou, W. COMRA's research on lifting motor pump. In Proceedings of the Seventh ISOPE Ocean Mining Symposium, Lisbon, Portugal, 1-6 July 2007; pp. 177-180.

10. Chung, J.S. An articulated pipe-miner system with thrust control for deep-ocean crust mining. Mar. GeoResour. Geotechnol. 1998, 16, 253-271. [CrossRef]

11. Liu, S.-J.; Wen, H.; Zou, W.-S.; Hu, X.-Z.; Dong, Z. Deep-Sea Mining Pump Wear Prediction Using Numerical Two-Phase Flow Simulation. In Proceedings of the 2019 International Conference on Intelligent Transportation, Big Data \& Smart City (ICITBS), Changsha, China, 12-13 January 2019; pp. 630-636.

12. Cader, T.; Masbernat, O.; Roco, M.C. LDV Measurements in a Centrifugal Slurry Pump: Water and Dilute Slurry Flows. J. Fluids Eng. 1992, 114, 606-615. [CrossRef]

13. Cader, T.; Masbernat, O; Roco, M.C. Two-Phase Velocity Distributions and Overall Performance of a Centrifugal Slurry Pump. J. Fluids Eng. 1994, 116, 316-323. [CrossRef]

14. Shi, B.; Wei, J.J.; Zhang, Y. Phase discrimination and a high accuracy algorithm for PIV image processing of particle-fluid two-phase flow inside high-speed rotating centrifugal slurry pump. Flow Meas. Instrum. 2015, 45, 93-104. [CrossRef]

15. Shi, B.; Wei, J.; Zhang, Y. A novel experimental facility for measuring internal flow of Solid-liquid two-phase flow in a centrifugal pump by PIV. Int. J. Multiph. Flow 2017, 89, 266-276. [CrossRef]

16. Kadambi, J.R.; Charoenngam, P.; Subramanian, A.; Wernet, M.P.; Sankovic, J.M.; Addie, G.; Courtwright, R. Investigations of Particle Velocities in a Slurry Pump Using PIV: Part 1, The Tongue and Adjacent Channel Flow. J. Energy Resour. Technol. 2004, 126, 271-278. [CrossRef]

17. Jialiang, X.; Zhang, H.; Lin, Z.; He, Z.; Xiang, J.; Su, X. Relationship between wear formation and large-particle motion in a pipe bend. R. Soc. Open Sci. 2019, 6, 181254. [CrossRef]

18. Tarodiya, R.; Gandhi, B.K. Numerical simulation of a centrifugal slurry pump handling solid-liquid mixture: Effect of solids on flow field and performance. Adv. Powder Technol. 2019, 30, 2225-2239. [CrossRef]

19. Zhu, H.; Zhu, J.; Rutter, R.; Zhang, H.-Q. A Numerical Study on Erosion Model Selection and Effect of Pump Type and Sand Characters in Electrical Submersible Pumps by Sandy Flow. J. Energy Resour. Technol. 2019, 141, 1-58. [CrossRef]

20. Huang, S.; Su, X.; Qiu, G. Transient numerical simulation for solid-liquid flow in a centrifugal pump by DEM-CFD coupling. Eng. Appl. Comput. Fluid Mech. 2015, 9, 411-418. [CrossRef]

21. Ndimande, C.; Cleary, P.; Mainza, A.; Sinnott, M. Using two-way coupled DEM-SPH to model an industrial scale Stirred Media Detritor. Miner. Eng. 2019, 137, 259-276. [CrossRef]

22. Chu, K.; Yu, A. Numerical Simulation of the Gas-Solid Flow in Three-Dimensional Pneumatic Conveying Bends. Ind. Eng. Chem. Res. 2008, 47, 7058-7071. [CrossRef]

23. Xiao, H.; Sun, J. Algorithms in a Robust Hybrid CFD-DEM Solver for Particle-Laden Flows. Commun. Comput. Phys. 2011, 9, 297-323. [CrossRef]

24. Gosman, A.D.; Loannides, E. Aspects of Computer Simulation of Liquid-Fueled Combustors. J. Energy 1983, 7, 482-490. [CrossRef]

25. Morsi, S.A.; Alexander, A.J. An investigation of particle trajectories in two-phase flow systems. J. Fluid Mech. 1972, 55, 193-208. [CrossRef]

26. Zhou, M.; Wang, S.; Kuang, S.; Luo, K.; Xing, J.; Yu, A. CFD-DEM modelling of hydraulic conveying of solid particles in a vertical pipe. Powder Technol. 2019, 354, 893-905. [CrossRef]

27. Liu, D.; Fu, X.; Wang, G. Volume fraction allocation using characteristic points for coupled CFD-DEM calculation. J. Tsinghua Univ. Technol. 2017, 57, 720. [CrossRef] 
28. Kang, Y.; Liu, S.; Zou, W.; Zhao, H.; Hu, X.-Z. Design and analysis of an innovative deep-sea lifting motor pump. Appl. Ocean Res. 2019, 82, 22-31. [CrossRef]

29. Kuntz, G. Advantages of Submersible Motor Pumps in Deep-Sea Mining. J. Pet. Technol. 1980, 32, 2241-2246. [CrossRef]

Publisher's Note: MDPI stays neutral with regard to jurisdictional claims in published maps and institutional affiliations.

(C) 2020 by the authors. Licensee MDPI, Basel, Switzerland. This article is an open access article distributed under the terms and conditions of the Creative Commons Attribution (CC BY) license (http://creativecommons.org/licenses/by/4.0/). 